\title{
Antispasmodic activities of the methanolic extract from aerial parts of Origanum species on excised rat ileum
}

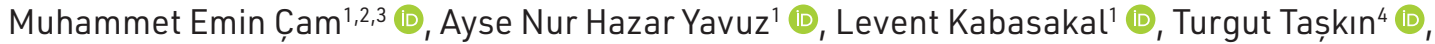 \\ Leyla Bitiș ${ }^{4}$ (1), Hatice Kübra Elçioğlu ${ }^{1}$ (i) \\ 'Marmara University, Faculty of Pharmacy, Department of Pharmacology, Istanbul, Turkey \\ ${ }^{2}$ University College London, Torrington Place, Department of Mechanical Engineering, London, UK \\ ${ }^{3}$ Marmara University, Center for Nanotechnology and Biomaterials Research, Turkey \\ "Marmara University, Faculty of Pharmacy, Department of Pharmacognosy, Istanbul, Turkey
}

ORCID IDs of the authors: M.E.C.. 0000-0001-5398-6801; A.N.H.Y. 0000-0003-0784-8779; L.K. 0000-0002-5474-6436;

T.T. 0000-0001-8475-6478; L.B. 0000-0003-1167-6666; H.K.E. 0000-0001-6386-1711

Cite this article as: Cam, M. E., Hazar Yavuz, A. N., Kabasakal, L., Taskin, T., Bitis, L., \& Elcioglu, H. K. (2020). Antispasmodic activities of the methanolic extract from aerial parts of Origanum species on excised rat ileum. Istanbul Journal of Pharmacy, 50 (3), 277-282.

\section{ABSTRACT}

Background and Aims: Origanum hypericifolium, Origanum minutiflorum, Origanum saccatum, and Origanum haussknechtii are some of the endemic Origanum species in Turkey. In the literature, besides the known effects of these Origanum species, no antispasmodic activity was determined. Therefore, we investigated Origanum species for possible antispasmodic effects to rationalize its traditional medicinal use. The present study aimed to investigate the antispasmodic activity of Origanum species with the organ bath.

Methods: Rats were divided into 5 groups. While no treatment was given to the control group, plant extracts were given to other groups. Ileal tissues taken by rats were used for evaluating the contraction responses elicited with potassium chloride $(\mathrm{KCl})$ and acetylcholine (ACh). Thereafter, the extracts of Origanum species were applied and cumulative concentrationresponse curves of these species were constructed in each experiment.

Results: All treatments with Origanum species have a relaxation effect on rat ileum as compared with the control group. According to the results of the isolated organ bath study, $\mathrm{KCl}$ and $\mathrm{ACh}$-induced ileum contractions were significantly decreased by all Origanum species.

Conclusion: Origanum species that were used in the present study can prevent smooth muscle contraction of ileum, and therefore they can be used to reduce intestinal spasms.

Keywords: Origanum hypericifolium, Origanum minutiflorum, Origanum saccatum, Origanum haussknechtii, Organ bath, Antispasmodic effect 


\section{INTRODUCTION}

Turkey, an important gene center for the Lamiaceae family, is represented by 45 genera, 546 species, and 730 taxa (Celik, Herken, Arslan, Ozel, \& Mercan, 2010). The endemism rate of the Lamiaceae family in Turkey is 53\% (Cam et al., 2019). Lamiaceae members are mainly common in the mountainous areas of the Mediterranean region of Turkey (Taskin, Cam, Taskin, \& Rayaman, 2019).

Oregano is a term that refers to members of Lamiaceae with many common characteristics, all of which contain carvacrol as the major component in their essential oils. Oregano includes Origanum, Thymus, Thymbra, Satureja, and Coridothymus of the Lamiaceae family. Origanum, one of these, is among important aromatic plants common in the world and comprises the largest portion of oregano used in trade (Baser, 2008). Hippocrates (500 BC) was aware of the antiseptic properties of oregano, and it is used for respiratory diseases and stomach pain. Dioscorides ( $1^{\text {st }}$ century AD), the author of the famous for Materia Medica, has proposed oregano tea for snakebites. Paracelsus $\left(16^{\text {th }}\right.$ century AD) suggested using oregano for the treatment of diarrhea, psoriasis, and fungal diseases (Baser, 2008).

Some of the endemic Origanum species in Turkey are Origanum hypericifolium Schwarz et Davis, Origanum minutiflorum Schwarz et Davis, Origanum saccatum Davis, and Origanum haussknechtii Boiss.. The first of these is O. hypericifolium, which is used in traditional medicine for the treatment of some diseases, especially diabetes (Ocak, Çelik, Özel, Korcan, \& Konuk, 2012). It mainly contains p-cymene, $\gamma$-terpinene, thymol, and carvacrol (Keskin, Ili, \& Sahin, 2012). Previous studies have shown that $O$. hypericifolium has antimicrobial (Celik et al., 2010) and antifungal (Ocak et al., 2012) activities. The second Origanum species is 0 . minutiflorum that has a-pinene, camphene, a-terpinene, p-cymene, carvacrol-methyl-ether, and carvacrol (Dadalioglu \& Evrendilek, 2004). According to the literature data, O. minutiflorum has antibacterial (Dadalioglu \& Evrendilek, 2004) and antifungal activity (Bayramoglu, Gülümser, \& Karaboz, 2006). The third Origanum species is O. saccatum which has a-pinene, camphene, p-cymene, thymol, and carvacrol (Tumen, Baser, Kirimer, \& Ozek, 1995). Previous studies have shown that O. saccatum has antimicrobial activity (Ozcan \& Chalchat, 2009). In addition to this, the fourth plant $O$. haussknechtii contains camphene, a-terpinene, and carvacrol (Baser, Kürkçüoglu, \&Tumen, 1998), and it is reported that it has antioxidant activity (Koseoglu, Taskin, Sadikoglu, \& Bitis, 2016).

In the literature, besides these known effects of the Origanum species mentioned above, none of them have been determined for their antispasmodic activities. Unlike these Origanum species, the antispasmodic effect was determined in some other Origanum species such as Origanum acutidens Handz.Mazz. (Goze et al., 2010), Origanum compactum Benth (Van Den Broucke \& Lemli, 1980), Origanum vulgare L (Khan, Bashir, Khan, \& Gilani, 2011), and Origanum majorana L (Makrane et al., 2019).

Plants and their products are used worldwide as traditional medicines, and these are all potential reservoirs for new drugs. Traditional medicinal plants have become very important in novel drug discovery due to their bioactive components (Taskin et al., 2018). Additionally, in recent years, increased interest has been shown in herbal products due to their strong effects and cheaper costs. Although new agents are developing, adverse effects are still a problem (Cam et al., 2017). At present, many people have consulted the use of natural remedies for the treatment of intestinal diseases due to their antispasmodic effects. One of the natural remedies used in the treatment of intestinal disease is the Origanum species with antispasmodic effects. Therefore, we investigated 0 . hypericifolium, O. minutiflorum, O. saccatum, and O. haussknechtii for possible antispasmodic effect and rationalization of their traditional medicinal use. The present study aimed to investigate antispasmodic activity of these Origanum species which have been used in folk medicine, in the organ bath system. Additionally, no acute or chronic toxicity related to these Origanum species were found in the literature.

\section{MATERIALS AND METHODS}

\section{Materials}

All chemicals used in the organ bath were purchased from Sigma (St. Louis, Missouri, USA).

\section{Collection of plant material}

O. hypericifolium, O. minutiflorum, O. saccatum, and 0 . haussknechtii were collected from Burdur, Isparta-Çandır, Antalya-Alanya, and Erzincan-Kemaliye provinces, respectively. The plant materials were identified by Dr. Narin Sadikoglu. Voucher specimens are deposited in the herbarium of the Faculty of Pharmacy, Inonu University, and herbarium voucher numbers: Origanum 2009/016, Origanum 2009/013, Origanum 2009/033, Origanum 2009/002, respectively.

\section{Methods \\ Preparation of the extracts}

The aerial parts of four dried Origanum species (20 g) were extracted with $100 \mathrm{ml}$ portions of methanol by maceration at room temperature $\left(25^{\circ} \mathrm{C}\right)$ for 7 days stirring several times until the extracts remained colorless. The extracts were filtered and evaporated to dryness under reduced pressure at $45{ }^{\circ} \mathrm{C}$ in a rotary evaporator. The crude extracts were then transferred to vials and kept at $+4{ }^{\circ} \mathrm{C}$. The crude extract was administered by diluting with distilled water at different concentrations before being used in the organ bath.

\section{Animals}

All animal experiments were carried out with the approval of the Marmara University Animal Experiments Local Ethics Committee (permission number: 51.2013.mar). Adult female Sprague-Dawley rats (250-350 g) ( $\mathrm{n}=8$ in each experiment) were obtained from Marmara University The Experimental Animal Implementation and Research Center (Istanbul, Turkey). The rats were housed under controlled temperature (20-23 ${ }^{\circ} \mathrm{C}$ ), in humidity (40-60\%), and light (12 h light/dark regime)regulated rooms. The animals were kept on a standard rodent pellet diet, with tap water available ad libitum. Before starting to the experiments, all necessary precautions were taken, and the factors that would adversely affect the parameters during the study were minimized. 


\section{Organ bath studies}

Healthy animals were divided into 5 groups. In the organ bath system, the control group was given methanol as a vehicle, while the other groups were given plant extracts. Ileum was removed from the rats after the rats were sacrificed by guillotine. $2 \mathrm{~cm}$-long part of ileum were sliced from all ileum; subsequently, the surrounding mesentery and fat tissues were carefully removed from ileum, and ileum was mounted vertically in an organ bath containing $20 \mathrm{ml}$ Tyrode buffer [composition $(\mathrm{mM}): \mathrm{NaCl}, 139.9 ; \mathrm{KCl}, 2.68 ; \mathrm{CaCl}_{2}, 1.8 ; \mathrm{MgCl}_{2}, 1.05 ; \mathrm{NaHCO}_{3}$, 11.9; $\mathrm{NaH}_{2} \mathrm{PO}_{4}, 0.42$; and glucose 5.55] at pH 7.40. The temperature of the organ bath was maintained at $37^{\circ} \mathrm{C}$, and carbogen (95\% $\mathrm{O}_{2}$ and $5 \% \mathrm{CO}_{2}$ gas mixture) was perfused through the bath. After mounting, ileum was equilibrated for approximately 60 min before the experiments were started with a buffer change every $15 \mathrm{~min}$. The initial tension of the preparation was set to about $1 \mathrm{~g}$. The tension of ileum was measured with an isometric force transducer (PowerLab, ADInstruments, Australia) and recorded on-line on a computer via a four-channel transducer data acquisition system using appropriate software (LabChart, ADInstruments, Australia).

\section{Contractility studies}

In the isolated ileum, rhythmic and tonic contractions were elicited with $80 \mathrm{mM} \mathrm{KCl}$ and $10^{-6} \mathrm{M}$ acetylcholine (ACh). Firstly, contraction with $\mathrm{KCl}$ was measured, this measurement was used for $\%$ of $\mathrm{KCl}$ maximum and then $\mathrm{KCl}$ was removed by changing the water bath three times. The contraciton responses of ACh were determined 15 minutes after removing $\mathrm{KCl}$ and Origanum species were cumulatively $(0.025,0.05,0.1,0.25,0.5,1 \mathrm{mg} / \mathrm{ml})$ administrated at the highest point of contraction with ACh. The relaxation response of ileal tissues were evaluated by adding cumulative concentrations of Origanum species on ACh induced precontractions. ACh induced contraction values were calculated according to $\mathrm{KCl}$. Following the addition of each concentration of Origanum species, the recording was performed for $120 \mathrm{~s}$. $\mathrm{KCl}$ induced contractions before the administration of Origanum species on rat ileum was obtained to investigate the viability of the tissues. Similar responses to $\mathrm{KCl}$ were observed for tissues among the groups. Concentration-response curves were fitted and areas under curves (AUC) were evaluated and analyzed statistically with Prism 6.05 (GraphPad Software Inc. San Diego, CA, USA). The AUC values and the maximal inhibitory effect of Origanum species $\left(E_{\max }\right)$ values were calculated according to \% relaxation response of tissues to ACh contraction.

\section{Statistical analysis}

All values are presented as mean \pm standard error of the mean (SEM). Differences in the contractile effect of $\mathrm{KCl}$ and $\mathrm{ACh}$ were analyzed using analysis of variance (ANOVA) tests with the Tukey multiple comparison test. Concentration-response curves were fitted, AUC determined, and $E_{\max }(\%)$ calculated with the Prism 6.05 software. The value of $p<0.05$ was considered statistically significant.

\section{RESULTS}

The main focus of our study is to clarify and compare the effects of some endemic species of Origanum in Turkey on rat ileum relaxations and contractions in the organ bath experi- ments. Therefore, the effect of these plants used in folk medicine was verified, and hence, the relaxation effect of Origanum species in various diseases can be utilized. The results obtained from the in vitro organ bath are given below according to responses to $\mathrm{KCl}$ and $\mathrm{ACh}$ contractions on rat ileum.

\section{Contraction responses of $\mathrm{KCl}$ on rat ileum}

The results of isolated organ bath experiments studied on rat ileum demonstrated that there are no significant differences between groups on contraction responses of the ileum tissues to $80 \mathrm{mM} \mathrm{KCl}$ which acts via voltage-gated calcium channels on all groups. It is clearly seen that the contraction responses of the ileum tissues to $80 \mathrm{mM} \mathrm{KCl}$ was similar before the administiration of Origanum species.

\section{Relaxation responses of cumulative concentrations of Origanum species on rat ileum}

The relaxation response of Origanum species at the concentration range of 0.025 to $1 \mathrm{mg} / \mathrm{ml}$ on ACh induced contraction on rat ileum was demonstrated in Figure 1. In the previous studies, some other Origanum species (O. acutidens, O. compactum, O. vulgare, and O. majorana) was found to display a relaxation response. Similar to the results of the previous studies, all treatments with Origanum species at the concentration range of 0.025-1 mg/ml have a relaxation response on rat ileum as compared with the control group. In comparison with the control group, the highest ileum relaxing effect of Origanum species belong to 0 . saccatum $(p<0.05)$, O. haussknechtii $(p<0.05)$, O. hypericifolium $(p<0.01)$, and O. minutiflorum $(p<0.001)$, respectively. Relaxation responses was augmented with the incerease in concentration of Origanum species in all groups. Thus, concentration-dependent relaxations were observed and these relaxing effects were completely recovered during washout period.

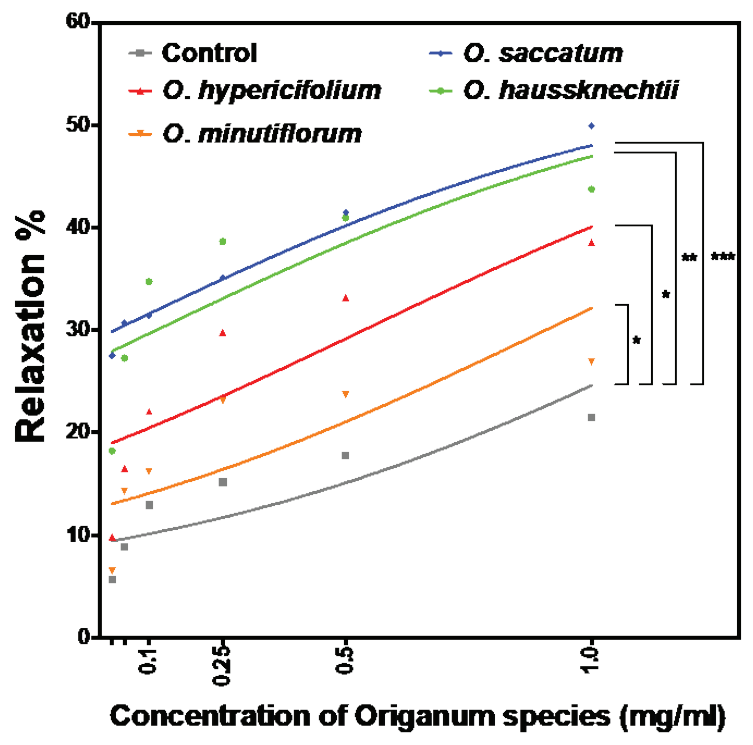

Figure 1. Changes in the relaxation responses of the cumulative Origanum species after contraction with ACh. Concentration of Origanum species: $0.025,0.05,0.1,0.25,0.5$, and $1 \mathrm{mg} / \mathrm{ml}$. Each group $(n=8)$ represents Mean \pm SEM. The statistical analyses were carried out with ANOVA tests with the Tukey multiple comparison test. ${ }^{*} p<0.05$, ${ }^{* *} p<0.01,{ }^{* * *} p<0.001$ vs control group. 
Besides, $E_{\max }$ and $A \cup C$ values for Origanum species were listed in Table 1. O. hypericifolium ( $p<0.05)$, O. saccatum ( $p<0.01)$, and 0 . haussknechtii $(p<0.05)$ treatments increased the $E_{\max }$ values compared to the control group.

\section{Table 1: Changes ( $E_{\max }$ and AUC values) in the relaxation response of Origanum species on $\mathrm{ACh}$ induced contractions in the rat ileum.}

\begin{tabular}{|c|c|c|}
\hline & $E_{\max }(\%)$ & $\operatorname{AUC}(\%)$ \\
\hline Control & $21.470 \pm 3.561$ & 16.77 \\
\hline 0. hypericifolium & $38.570 \pm 4.301^{*}$ & 30.99 \\
\hline 0. minutiflorum & $26.870 \pm 2.704$ & 22.46 \\
\hline 0. saccatum & $49.950 \pm 5.405^{* *}$ & 39.72 \\
\hline O. haussknechtii & $43.750 \pm 5.21^{1 *}$ & 38.75 \\
\hline
\end{tabular}

\section{Changes in ACh induced contraction with the presence of Origanum species}

The effects of different concentrations (0.025-1 mg/ml) of Origanum species on $\mathrm{ACh}$ induced contractions in the rat ileum were given in Figure 2. O. hypericifolium, O. minutiflorum, $\mathrm{O}$. saccatum, and $O$. haussknechtii reduced contractility induced by $A C h$ on rat ileum as compared with control group $(p<0.05$, $p<0.05, p<0.05$ and $p<0.01$, respectively). Origanum species showed concentration-dependent inhibition on Ach induced contractios in rat ileum.

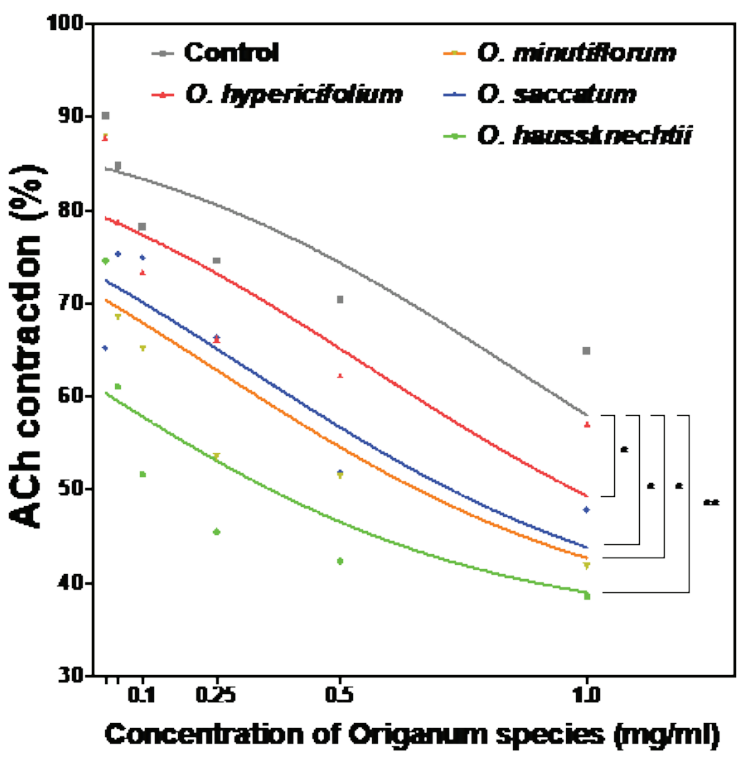

Figure 2. Changes in the ACh induced contraction responses after administration of cumulative Origanum species. Concentrations of Origanum species: $0.025,0.05,0.1,0.25,0.5$, and $1 \mathrm{mg} / \mathrm{ml}$. Each group $(n=8)$ represents Mean \pm SEM. The statistical analyses were carried out with ANOVA tests with the Tukey multiple comparison test. ${ }^{*} p<0.05$, ${ }^{* *} \mathrm{p}<0.01$.
Besides, $E_{\max }$ and AUC values for Origanum species were listed in Table 2. O. saccatum $(p<0.01)$ and O. haussknechtii $(p<0.05)$ treatments reduced $E_{\max }$ values compared to control group.

Table 2: Changes ( $E_{\max }$ and AUC values) in the ACh induced contractions in the presence of Origanum species on the rat ileum.

\begin{tabular}{|lcc|}
\hline & $\mathrm{E}_{\max }(\%)$ & AUC (\%) \\
\hline Control & $90.110 \pm 3.310$ & 72.10 \\
O. hypericifolium & $87.780 \pm 2.528$ & 64.64 \\
O. minutiflorum & $87.980 \pm 5.301$ & 52.96 \\
O. saccatum & $65.220 \pm 13.980^{\star *}$ & 57.88 \\
O. haussknechtii & $74.550 \pm 5.172^{*}$ & 45.17 \\
\hline${ }^{*}<0.05,{ }^{* *}<<0.01$ vs control group (Mean \pm SEM). AUC: Area under \\
the curve. $\mathrm{E}_{\max }(\%)$ : the maximum contraction of ACh. \\
\hline
\end{tabular}

\section{DISCUSSION}

In literature, the antispasmodic activity of $O$. acutidens essential oil in rat ileum was investigated by organ bath study. In that study, the essential oil of $O$. acutidens was applied in cumulative doses $(0.1,0.5$, and $1 \mathrm{mg})$ and decreased ileal tissue contraction. According to their results, the antispasmodic effect of that essential oil is strong, concentration-independently and fully reversible (Goze et al., 2010). In another study, which investigated the antispasmodic activity of $O$. compactum, an organ bath study with the guinea-pig ileum and duodenum, and the rat fundus strip and duodenum were performed. According to their results, O. compactum showed antispasmodic activity on smooth muscles. In that study, it was suggested that the effects of $O$. compactum on muscle relaxation were caused by a decrease in the presence of the calcium for contraction of muscle due to inhibition of intracellular $\mathrm{Ca}^{+2}$ release and extracellular $\mathrm{Ca}^{+2}$ influx in the smooth muscle cells (Van Den Broucke \& Lemli, 1980). In another study, the antispasmodic activity of $O$. vulgare was investigated with an organ bath study in the strips of rabbit urinary bladder. O. vulgare inhibited carbachol and $\mathrm{K}^{+}$-induced contractions in concentration-dependent manner (Khan et al., 2011). The antispasmodic activity of the essential oil from the aerial part of $O$. majorana on muscle relaxation was investigated on rabbit and rat intestinal smooth muscle. According to these results, O. majorana essential oil inhibited the carbachol and $\mathrm{KCl}$-induced contraction of tissue (Makrane et al., 2019). We investigated the antispasmodic effect of Origanum species and examined their relaxation response in $A C h\left(10^{-6} \mathrm{M}\right)$ induced contractions on rat ileum. As obtained from our results, Origanum species reduced contractions on rat ileum.

The membrane of smooth muscle includes more voltagedependent $\mathrm{Ca}^{+2}$ channels than skeletal muscle, but on the contrary, it contains much less voltage-dependent sodium channels. For this reason, calcium ions are responsible for contracting as they flow from the slow calcium-sodium channels to the fiber by the action of $\mathrm{KCl}$ (Ratz, Berg, Urban, \& Miner, 2005). It is known that $\mathrm{KCl}$ at high concentrations causes the 
contraction of smooth muscle by the opening of the voltageinduced L-type calcium channels, thus resulting in the contraction of the smooth muscles because of the influx of extracellular Ca²+ (Khan et al., 2011).

ACh, due to its effect on muscarinic $M_{4}$ receptors, leads to contraction by decreasing cyclic adenosine monophosphate (CAMP) levels, increasing the amount of intracellular calcium or affecting nicotinic receptor and opening ion channels, and thus produce depolarization(Nausch, Heppner, \& Nelson, 2010). It is also well known that contraction induced by $\mathrm{K}^{+}$in smooth muscles is caused by an increase in $\mathrm{Ca}^{2+}$ flow through voltage-gated $\mathrm{Ca}^{2+}$ channels, and therefore, any substance that inhibits high $\mathrm{K}^{+}$mediated contractions of smooth muscles is claimed to be an inhibitor of $\mathrm{Ca}^{2+}$ flux (Chiwororo \& Ojewole, 2009). $\mathrm{KCl}$ induced contraction on ileum smooth muscle is mainly caused by calcium influx through voltage-sensitive calcium channels (Ponce-Monter et al., 2006). The present findings show that the Origanum species inhibit ACh induced ileum contractions acting on the stress-sensitive calcium channels. These Origanum species led to concentration-dependent and reversible inhibition of the isolated rat ileum contractions. The contraction caused by ACh was inhibited by Origanum species in a concentration-dependent manner.

Additionally, according to our results, the inhibitory effects of Origanum species induced by ACh is not reversible. These effects are only reduced and eliminated by washing tissues. The relative decrease in the effects of the extract after tissue washing can be related to the removal of the extract from the surface of receptors. Moreover, prolonged ileum contractions without a reduction in contractile force with ACh in control tissues showed that the decrease in contractile strength was due to the performance of the extract rather than muscle fatigue.

Phytochemical studies reveal the presence of various substances in plants. The activities observed in the extracts of the Origanum species that we tested are probably due to the presence of these phytochemicals. For example, it is known that flavonoids exhibit antispasmodic activity. However, other phytochemicals in the extracts also contribute to the effects found (Tumen et al., 1995). Considering the phytochemical studies on these Origanum species, these plants contain tannins, flavonoids, sitosterols, phenolic glycosides, phenolic terpenoids, arbutin, and numerous essential oil molecules.

Carvacrol $\left(\mathrm{C}_{10} \mathrm{H}_{14} \mathrm{O}\right.$, a monoterpenoid phenol), one of the major components of Origanum species, is investigated in the Origanum species extract and it is known to have antispasmodic activity. Thus, the antispasmodic activity observed in the present study can be attributed to the carvacrol of Origanum (Baser, 2008). It is reported that carvacrol content of the O. hypericifolium, O. minutiflorum, O. saccatum, O. haussknechtii are 42-82\% (Baser, Ermin, Kurkcuoglu, \& Tumen, 1994), 34-64\% (Baser, Tümen, \& Sezik, 1991), 6.36-7.18\% (Tumen et al., 1995), and 4.34\% (Koseoglu et al., 2016), respectively. In addition to carvacrol, it is reported that thymol, another component of Origanum species, has antispasmodic effect; however, p-cymene has no antispasmodic effect. According to the study, which is a continuation of the same study, the basic fact emerging from the results is that pharmacological inhibition of smooth muscle activity plays a major role in the non-specific and non-competitive antagonism of thymol and carvacrol. Changes in the degree of effect of the Origanum species whose effects were investigated in our study are likely to vary according to the presence of carvacrol, thymol, and other components at different rates. However, further investigations are needed on that subject. Additionally, an edible plant with a long history of medical use is considered to be relatively safe, but detailed studies of the safety profile are needed before being recommended for clinical use.

Any report of antispasmodic properties of these Origanum species on the literature was not mentioned before. According to our results, the extracts of Origanum species reduced smooth muscle contraction on rat ileum. The effects of the extract were concentration-dependent and completely reversed during washing. The exact mechanism of Origanum species may be related to $\mathrm{Ca}^{2+}$ level changes in the ileum smooth muscle in the presence of extract. The antispasmodic effect of the extract observed in this study supports the clinical efficacy and use of the extracts of Origanum species in the treatment of spasmodic disorders. Further studies are needed to explain the underlying mechanism of action of Origanum species and evaluate its use in folk medicine. Due to the antispasmodic activity of Origanum species, these plants can be considered as a natural source and freely used in the food and pharmaceutical industry.

\section{CONCLUSION}

The antispasmodic effects of some Origanum species, such as Origanum hypericifolium, Origanum minutiflorum, Origanum saccatum, and Origanum haussknechtii, were investigated. The Origanum species have shown significant antispasmodic activity by acting on various pharmacological pathways. The contraction caused by ACh was inhibited by Origanum species in a concentration-dependent manner. Consequently, Origanum species can cause concentration-dependent and reversible inhibition of spontaneous contractions on isolated rat ileum, and they can inhibit contraction of the smooth muscle of ileum on rats. Thus, it can be used to decrease intestinal spasms. Further studies are needed to determine the mechanism of action and major effective compounds.

Peer-review: Externally peer-reviewed.

Ethics Committee Approval: All animal experiments were carried out with the approval of the Marmara University Animal Experiments Ethics Committee (number 51.2013.mar).

Author Contributions: Conception/Design of Study- H.K.E., M.E.Ç., A.N.H.Y., L.K.; Data Acquisition- M.E.Ç., A.N.H.Y.; Data Analysis/Interpretation- M.E.Ç., L.K.; Drafting Manuscript- M.E.Ç., A.N.H.Y.; Critical Revision of Manuscript- L.K., H.K.E.; Final Approval and AccountabilityM.E.Ç., A.N.H.Y., L.K., T.T., L.B., H.K.E.; Technical or Material Support-T.T.; Supervision- L.B.

Conflict of Interest: The authors have no conflict of interest to declare.

Financial Disclosure: This study was supported by Marmara University, Scientific Research Projects Committee (MU-BAPKO; Project number: SAG-B-131113-0419). 


\section{REFERENCES}

- Baser, K.H.C. (2008). Biological and pharmacological activities of carvacrol and carvacrol bearing essential oils. Current Pharmacological Design, 14, 3106-3019. https://dx.doi. org/10.2174/138161208786404227

- Baser, K.H.C., Ermin, N., Kurkcuoglu, M., \&Tümen, G. (1994). Essential Oil of Origanum hypericifolium O. Schwarz et P. H. Davis. The Journal of Essential Oil Research, 6(6), 631-633. https://dx.doi.org/ 10.1080/10412905.1994.9699355

- Baser, K.H.C., Kürkçüoglu, M., \& Tumen, G. (1998). Composition of the Essential Oil of Origanum haussknechtii Boiss. The Journal of Essential Oil Research, 10, 227-228. https://dx.doi.org/10.1080/10 412905.1998.9700888

- $\quad$ Baser, K.H.C., Tümen, G., \& Sezik, E. (1991). The Essential Oil of Origanum minutiflorum O. Schwarz and P. H. Davis. The Journal of Essential Oil Research, 3(6), 445-446. https://dx.doi.org/10.1080/10 412905.1991.9697982

- Bayramoglu, E., Gülümser, G., \& Karaboz, I. (2006). Ecological and innovative fungicide for the leather industry: Essential oil of Origanum minutiflorum. Journal of American Leather Chemists Association, 101, 96-104.

- Cam, M.E., Yildiz, S., Ertas, B., Acar, A.E., Taskin, T., \& Kabasakal, L. (2017). Antidiabetic effects of Salvia triloba and Thymus praecox subsp. skorpilii var. skorpilii in a rat model of streptozotocin/nicotinamide-induced diabetes. Marmara Pharmaceutical Journal. 21(4), 818-827. https://dx.doi.org/10.12991/mpj.2017.8

- Cam, M.E., Hazar-Yavuz, A.N., Yildiz, S., Ertas, B., Ayaz Adakul, B., Taskin, T., Alan, S., \& Kabasakal, L. (2019). The methanolic extract of Thymus praecox subsp. skorpilii var. skorpilii restores glucose homeostasis, ameliorates insulin resistance and improves pancreatic beta-cell function on streptozotocin/nicotinamide-induced type 2 diabetic rats. Journal of Ethnopharmacology, 231, 29-38. https://dx.doi.org/10.1016/j.jep.2018.10.028

- Celik, A., Herken, E.N., Arslan, I., Ozel, M.Z., \& Mercan, N. (2010). Screening of the constituents, antimicrobial and antioxidant activity of endemic Origanum hypericifolium O. Schwartz \& P.H. Davis. Natural Product Research, 24, 1568-1577. https://dx.doi.org/10 $.1080 / 14786419.2010 .496366$

- Chiwororo, D.H.W., \& Ojewole, A.O.J. (2009). Spasmolytic effect of Psidium guajava Linn. (Myrtaceae) leaf aqueous extract on rat isolated uterine horns. Journal of Smooth Muscle Research, 45, 31-38. https://dx.doi.org/10.1540/jsmr.45.31

- Dadalioglu, I., \& Evrendilek, G.A. (2004). Chemical compositions and antibacterial effects of essential oils of Turkish oregano (Origanum minutiflorum), bay laurel (Laurus nobilis), Spanish lavender (Lavandula stoechas L.), and fennel (Foeniculum vulgare) on common foodborne pathogens. Journal of Agricultural and Food Chemistry, 52, 8255-8260. https://dx.doi.org/10.1021/jf049033e

- Goze, I., Alim, A., Cetinus, S.A., Cetin, A., Durmus, N., Atas, A.T., \& Vural, S. (2010). In vitro antimicrobial, antioxidant, and antispasmodic activities and the composition of the essential oil of Origanum acutidens (Hand.-Mazz.) letswaart. Journal of Medicinal Food, 13, 705-709. https://dx.doi.org/10.1089/jmf.2009.0094
- Keskin, N., Ili, P., \& Sahin, B. (2012). Histochemical demonstration of mucosubstances in the mouse gastrointestinal tract treated with Origanum hypericifolium O. Schwartz and P.H. Davis extract. African Journal of Biotechnology, 11, 2436-2444. https://dx.doi. org/10.5897/AJB11.1930

- Khan, A., Bashir, S., Khan S.R., \& Gilani, A.H. (2011) Antiurolithic activity of Origanum vulgare is mediated through multiple pathways. BMC Complementary and Alternative Medicine, 11(1):96. https://dx.doi.org/10.1186/1472-6882-11-96

- Koseoglu, A., Taskin, T., Sadikoglu, N., \& Bitis, L. (2016) Antioxidant Capacity of Methanol Extract of Turkish Endemic Species Origanum haussknechtii. Chemistry, 23, 289-292.

Makrane, H., Aziz, M., Berrabah, M., Mekhfi, H., Ziyyat, A., Bnouham, M., Legssyer, A., Elombo, F.K., Gressier, B., \& Eto, B. (2019). Myorelaxant Activity of essential oil from Origanum majorana L. on rat and rabbit. Journal of Ethnopharmacology, 228, 40-49. https://dx.doi. org/10.1016/j.jep.2018.08.036

- $\quad$ Nausch, B., Heppner, T., \& Nelson, T.M. (2010). Nerve-released acetylcholine contracts urinary bladder smooth muscle by inducing action potentials independently of IP3-mediated calcium release. American Journal of Physiolology-Regulatory, Integrative and Comparative Physiology, 299, 878-888. https://dx.doi.org/10.1152/ajpregu.00180.2010

- $\quad$ Ocak, I., Çelik, A., Özel, M.Z., Korcan, E., \& Konuk, M. (2012). Antifungal Activity and Chemical Composition of Essential Oil of Origanum Hypericifolium. International Journal of Food Properties, 15, 38-48. https://dx.doi.org/10.1080/10942911003687249

Ozcan, M., \& Chalchat, J.C. (2009). Chemical composition and antimicrobial properties of the essential oil of Origanum saccatum L. Journal of Food Safety, 29, 617-628. https://dx.doi.org/10.1111/ j.1745-4565.2009.00181.x

- Ponce-Monter, H., Pérez, S., Zavala, M., Pérez-González, C., Meckes, M., Macias, A., \& Campos, M. (2006). Relaxant Effect of Xanthomicrol and 3a-Angeloyloxy-2a-hydroxy-13,14Z-dehydrocativic Acid from Brickellia paniculata on Rat Uterus. Biological and Pharmaceutical Bulletin, 29, 1501-1503. https://dx.doi.org/10.1248/ bpb.29.1501

- Ratz, P., Berg, M.K., Urban, H.N., \& Miner, A. (2005). Regulation of smooth muscle calcium sensitivity: $\mathrm{KCl}$ as calcium-sensitizing stimulus. The American Journal of Physiology: Cell Physiology, 288, 769-783. https://dx.doi.org/10.1152/ajpcell.00529.2004

- Taskin, T., Cam, M.E., Bulut, G., Hazar-Yavuz, A.N., Kabasakal, L., \& Bitis, L. (2018). Antioxidant and anti-inflammatory activities of Phlomis pungens and Coridothymus capitatus. Marmara Pharmaceutical Journal, 22, 80-85. https://dx.doi.org/10.12991/mpj.2018.44

- Taskin, T., Cam, M.E., Taskin, D., \& Rayaman, E.. (2019). In vitro and In vivo biological activities and phenolic characterization of Thymus praecox subsp. skorpilii var. skorpilii. Journal of Food Measurement and Characterization, 13, 536-544. https://dx.doi.org/10.1007/ s11694-018-9967-1

- Tumen, G., Baser, K., Kirimer, N., \& Ozek, T. (1995). Essential oil of Origanum saccatum PH Davis. The Journal of Essential Oil Res, 7, 175-176. https://dx.doi.org/10.1080/10412905.1995.9698493

- $\quad$ Van Den Broucke, C., Lemli, J. (1980). Antispasmodic activity of Origanum compactum. Planta Medica, 38, 317-331. https:// dx.doi.org/10.1055/s-2008-1074884 